\title{
Assessment of calving progress and reference times for obstetric intervention during dystocia in Holstein dairy cows
}

\author{
G. M. Schuenemann, ${ }^{1}$ I. Nieto, S. Bas, K. N. Galvão, ${ }^{2}$ and J. Workman \\ Department of Veterinary Preventive Medicine, The Ohio State University, Columbus 43210
}

\begin{abstract}
The objectives of this observational study were (1) to assess the time from the appearance of the amniotic sac (AS) or feet outside the vulva to birth in Holstein cows (primiparous and multiparous) with (dystocia) or without assistance (eutocia) at calving, and (2) to estimate reference times to be used as guidelines for obstetric intervention in Holstein cows that need assistance during difficult births. Cows $(\mathrm{n}=92)$ from 1 commercial dairy operation were used in this study. Periparturient dairy cows (primiparous, $\mathrm{n}=58$; multiparous, $\mathrm{n}=34$ ) were placed in a maternity pen and constantly monitored until birth. The calving ease of cows, time from AS or feet appearance to birth, calving progress from a subset of 15 cows (frequency and duration of abdominal contractions during labor), calf birth weight, calf sex, and stillbirths (born dead or died within $24 \mathrm{~h}$ after birth) were recorded. The reference times for obstetric intervention during dystocia were estimated based on values from unassisted births (normal). The normal range of times from the appearance of AS or feet outside the vulva to birth was estimated based on the mean +2 standard deviations (SD) of unassisted births. According to farm protocol, assistance was provided to cows without calving progress $80 \mathrm{~min}$ after AS appearance or earlier (e.g., to correct malpositions). Cows with dystocic births had a longer time from AS appearance to birth and increased incidence of stillbirth compared with cows with eutocic calvings. After the appearance of the AS, calving progress was evident every $15 \mathrm{~min}$ for eutocic births. The estimated reference times (mean + $2 \mathrm{SD}$ ) from AS appearance to birth were $69.7 \mathrm{~min}$ and from feet appearance to birth were $64.6 \mathrm{~min}$ for eutocic births. Findings from this study suggested that calving personnel should start assisting cows 70 min after AS appearance (or $65 \mathrm{~min}$ after feet appearance) outside the vulva. The time spent in labor (straining) combined
\end{abstract}

\footnotetext{
Received April 11, 2011.

Accepted July 10, 2011.

${ }^{1}$ Current address: Department of Large Animal Clinical Sciences, College of Veterinary Medicine, University of Florida, Gainesville 32610 .

${ }^{2}$ Corresponding author: schuenemann.5@osu.edu
}

with the time from the appearance of the AS or feet to birth, and the assessment of calving progress (as described for eutocic births) should be used as guidelines for obstetric intervention during difficult births under field conditions. These reference times should be interpreted in combination with adequate obstetrical knowledge and examination.

Key words: calving management, obstetric intervention, dystocia

\section{INTRODUCTION}

Dystocia has been defined as a difficult birth resulting in prolonged calving or severe assisted extraction of the calf at birth (Mee, 2004). Assisted calving has been defined as a birth in which assistance is required (e.g., correction of malposition), but this may not necessarily result in dystocia (Mee, 2004). The amount of assistance that is provided during parturition determines the degree of dystocia. For instance, a 1 to 3 scale $(1=$ no assistance; $2=$ slight assistance; $3=$ needed assistance; Meyer et al., 2001), a 1 to 5 scale $(1=$ no assistance; 2 = assistance by one person without the use of mechanical traction; $3=$ assistance by 2 or more people; $4=$ assistance with mechanical traction; $5=$ surgical procedure; Lombard et al., 2007), or a combination of these have been reported. Meyer et al. (2001) evaluated 666,341 dairy calving records and estimated the proportion of dystocia to be $28.6 \%$ in primiparous and $10.7 \%$ in multiparous cows. Overall, the incidence of dystocia (assistance required during calving) is higher in primiparous $(19 \%)$ than in multiparous cows $(11 \%$; USDA, 2010). However, in some dairy herds, more than half $(51.2 \%)$ of the calves from primiparous cows required assistance at birth (Lombard et al., 2007). Dystocia increases the incidence of stillbirths (Mee, 2004; Lombard et al., 2007) and calf mortality within 30 d postcalving (Mee, 2008; Lombard et al., 2007). In addition, dystocia increases the likelihood of trauma on the dam (i.e., paresis), uterine disorders (Sheldon et al., 2009), and decreased milk yield (Dematawewa and Berger, 1997).

The primary causes of dystocia are fetal-maternal size mismatch $(>50 \%$ of obstetrical cases; Meijer- 
ing, 1984; Berger et al., 1992), fetal malpresentation (20-40\% of obstetrical cases; Meijering, 1984; Mee, 2008), and dam-related causes such as uterine torsion ( $<10 \%$ of obstetrical cases; Frazer et al., 1996; Mee, 2008 ) and hypocalcemia ( $<17 \%$ of the obstetrical cases; Curtis et al., 1983). These percentages were determined based on the total number of obstetrical cases referred to veterinary hospitals or practices, which are likely the most severe cases and may not reflect the actual prevalence. Fetal-maternal size mismatch and vulval stenoses are the most frequent causes of dystocia in primiparous dams (Mee, 2008), whereas fetal malpresentation or maternal-related causes (e.g., uterine torsion, hypocalcemia, cervical stenosis) are the most frequent causes of dystocia in multiparous dairy cows (Mee, 2008). Training on calving management for dairy personnel has been reported as a top priority (Lombard et al., 2007) to mitigate the negative effects of dystocia, especially to reduce the incidence of stillbirths and metritis. To reduce the sequelae of dystocia, the educational program should be able to provide clear recommendations to participants on the signs of imminent birth over time (e.g., calving progress), when and how it is appropriate to intervene, and hygiene practices, among others. Describing the signs and timing of eutocic (normal) as well as dystocic (abnormal) births is paramount to determine the appropriate time for intervention in parturient Holstein cows. Therefore, the objectives of this observational study were (1) to assess the time from the appearance of the amniotic sac (AS) or feet outside the vulva to birth in Holstein cows with (dystocia) or without assistance (eutocia) at calving, and (2) to estimate reference times to be used as guidelines for obstetric intervention in Holstein cows that need assistance during difficult births (dystocia).

\section{MATERIALS AND METHODS}

\section{Animal, Facilities, and Feeding}

Ninety-two Holstein cows from 1 commercial dairy operation were used in this observational study. Periparturient primiparous (PRIM, $\mathrm{n}=58$ ) and multiparous (MULT, $\mathrm{n}=34$ ) dairy cows were housed in freestall barns bedded with sand. Cows were fed twice daily, in the morning and afternoon, with a TMR formulated to meet or exceed dietary nutritional requirements for dry dairy cows (NRC, 2001). Pregnant cows were located in the prepartum pen, which was located next to the maternity pen. Cows at labor were placed in an individual maternity pen (approximately $20 \mathrm{~m}^{2}$ ) padded with wheat straw bedding and constantly monitored until birth. Cows were able to move freely within the maternity pen. This study was conducted in July and
August 2010. The observational procedures described below were determined as exempt from review by The Ohio State University Veterinary Teaching Hospital Clinical Research Advisory Committee.

\section{Observation of Calving Signs}

Prior to the start of this observational study, calving management training (i.e., signs of calving, dystocia management, frequency of observations, and hygiene practices) was provided to calving personnel. The calving ease of cows (assistance provided at birth) was recorded using a 1 to 4 scale $(1=$ no assistance provided; $2=$ light assistance by one person without the use of mechanical traction; $3=$ mechanical extraction of the calf with an obstetric calf-puller; and $4=$ severe dystocia: surgery or fetotomy needed). Timing from AS appearance to birth, timing from feet appearance to birth, and stillbirths (born dead or died within $24 \mathrm{~h}$ after birth) were recorded. Slight protrusion of the AS outside of the vulva was defined as the onset of AS appearance. Approximately every $1 \mathrm{~h}$, calving personnel walked through the prepartum pen looking for cows with signs of imminent calving (presence of mucus-blood around the perineum or the onset of AS appearance outside the vulva). Those cows showing signs of imminent calving were immediately moved to an individual maternity pen and constantly monitored until birth by one of the research team veterinarians positioned outside of the maternity pen. Those cows with advanced AS appearance (AS hanging outside of the vulva) or showing feet did not meet the criteria and were not enrolled in the study. According to farm protocol, assistance was provided to cows without calving progress at approximately $80 \mathrm{~min}$ after the onset of AS appearance, or earlier if only one foot had been exteriorized outside the vulva. On a few occasions, timing exceeded 80 min because 2 cows needed assistance at the same time. Immediately following calving, cows were moved to the fresh pen.

\section{Description of Calving Progress and Intervention}

Calving progress (appearance of AS, showing feet, nose-head, and shoulder of the calf outside the vulva until birth) and the frequency and duration (s) of abdominal contractions during the labor period were recorded in a subset of cows with unassisted $(\mathrm{n}=10)$ or assisted births $(\mathrm{n}=5)$. The duration of abdominal contractions (s) was estimated using the frame counter of a digital video camera (Sony, Tokyo, Japan). Calf birth weights were recorded using a mechanical hanging scale (Pelouze Rubbermaid, Winchester, VA) immediately after birth. All cows had their BCS (scale 0-5; Ferguson et al., 1994) recorded immediately after calving. 


\section{Statistical Analysis}

The time from AS appearance to birth (min) and from feet appearance outside the vulva to birth (min), the frequency and duration (s) of abdominal contractions, calf birth weights $(\mathrm{kg})$, and the incidence of stillbirths (born dead or died within $24 \mathrm{~h}$ after birth) in PRIM and MULT were evaluated. Data pertaining to calving progress over time (from AS or feet appearance to birth, and the frequency and duration of abdominal contractions) were summarized and reported as mean values every $3 \mathrm{~min}$ to illustrate the events leading to birth (Figures 1, 2, and 3).

Time (min) from AS appearance to birth, from feet appearance outside the vulva to birth (min), calf birth weight $(\mathrm{kg})$, and proportion of stillbirths were analyzed using the mixed model of SAS (Proc Mixed; SAS Institute, 2009). A model procedure that included parity (PRIM or MULT), sex of the calf, calving (assisted or unassisted), BCS at calving, stillbirths, and calf weight at birth was used to compare differences between assisted and unassisted births. Nonsignificant variables were eliminated from the logistic model one at a time using the Wald statistic backward selection criterion $(P>0.15)$. Scores of 2 to 4 from assisted births were combined for the statistical analysis. The reference times for obstetric intervention during dystocia were estimated based on values from unassisted births. The estimates (time from AS appearance to birth and from feet appearance to birth, and calf birth weight) from the model were reported as least squares means \pm SEM. The reference times for obstetric intervention (from AS or feet of the calf appearance to birth) were estimated based on the mean \pm 2 SD (Wenz et al., 2011) of unassisted births (eutocia). In addition, the upper limits of $95 \%$ CI (Smit et al., 2003) were reported for unassisted (eutocia) and assisted births (dystocia). The 95\% CI was computed by including the CL option in the LSMEANS statement. Differences in individual least squares means were adjusted by using Tukey-Kramer method. A $P<0.05$ was considered statistically significant.

\section{RESULTS AND DISCUSSION}

\section{Calving Signs and Progress During Labor}

The frequency and duration of abdominal contractions, the signs of imminent birth, and calving progress were recorded for eutocic $(n=10$; Figures 1 and 2$)$ and

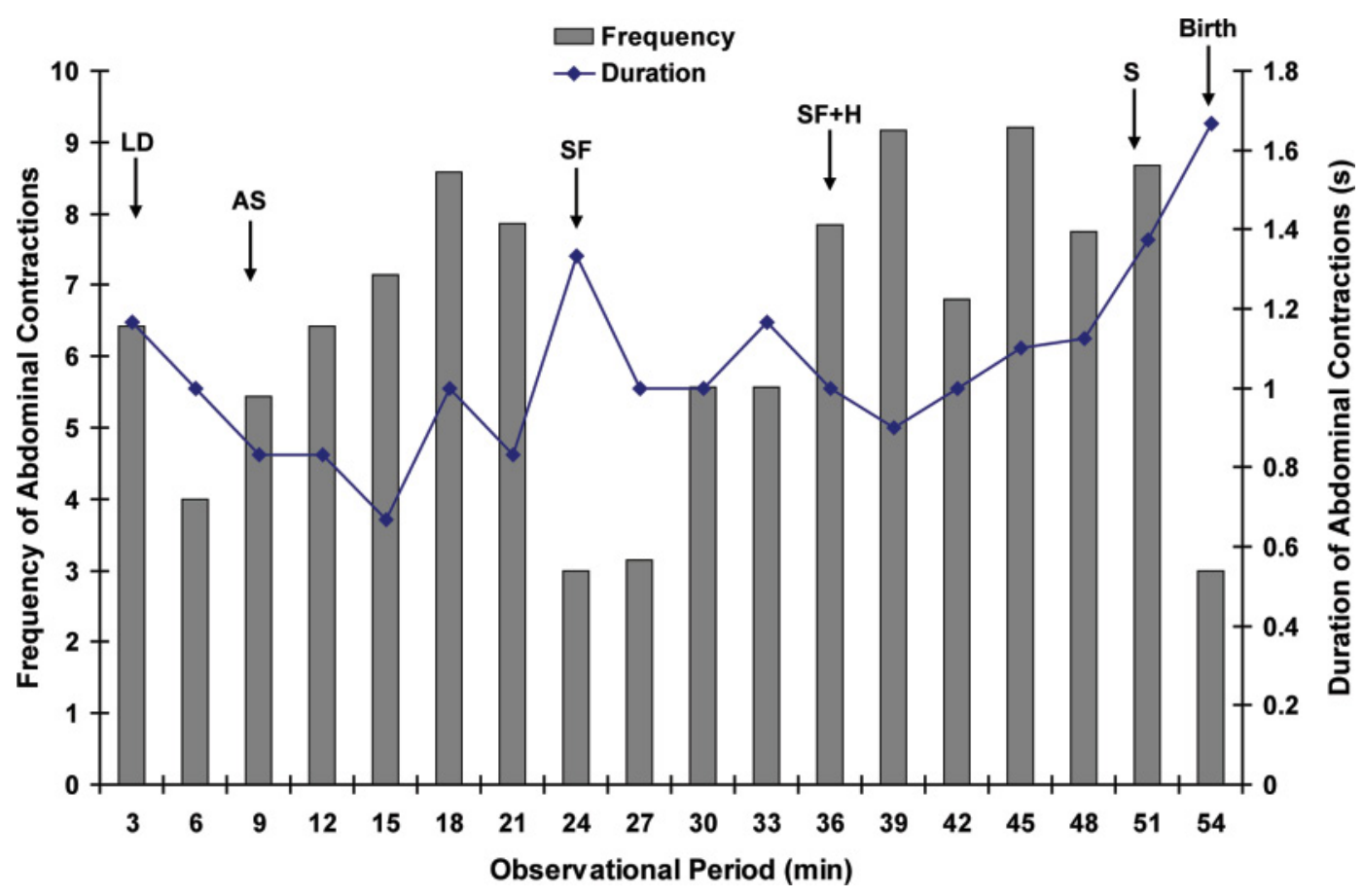

Figure 1. Mean frequency and duration (s) of abdominal contractions during the labor stage of unassisted births (eutocia) in 5 multiparous dairy cows. Periparturient multiparous cows $(\mathrm{n}=5)$ were placed in an individual maternity pen and constantly monitored until birth. Cow behavior (lying down or standing up), signs and progress of imminent birth (amniotic sac appearance, showing feet, head, shoulder, and birth), and the onset of frequency and duration of abdominal contractions were recorded during the labor stage of unassisted births (eutocia). The following calving signs over time (indication of birth progress) were recorded: LD = lying down; $\mathrm{AS}=$ amniotic sac appearance; $\mathrm{SF}=$ showing feet; $\mathrm{SF}+\mathrm{H}=$ showing feet and head; $\mathrm{S}=$ shoulder; and birth. Color version available in the online PDF. 


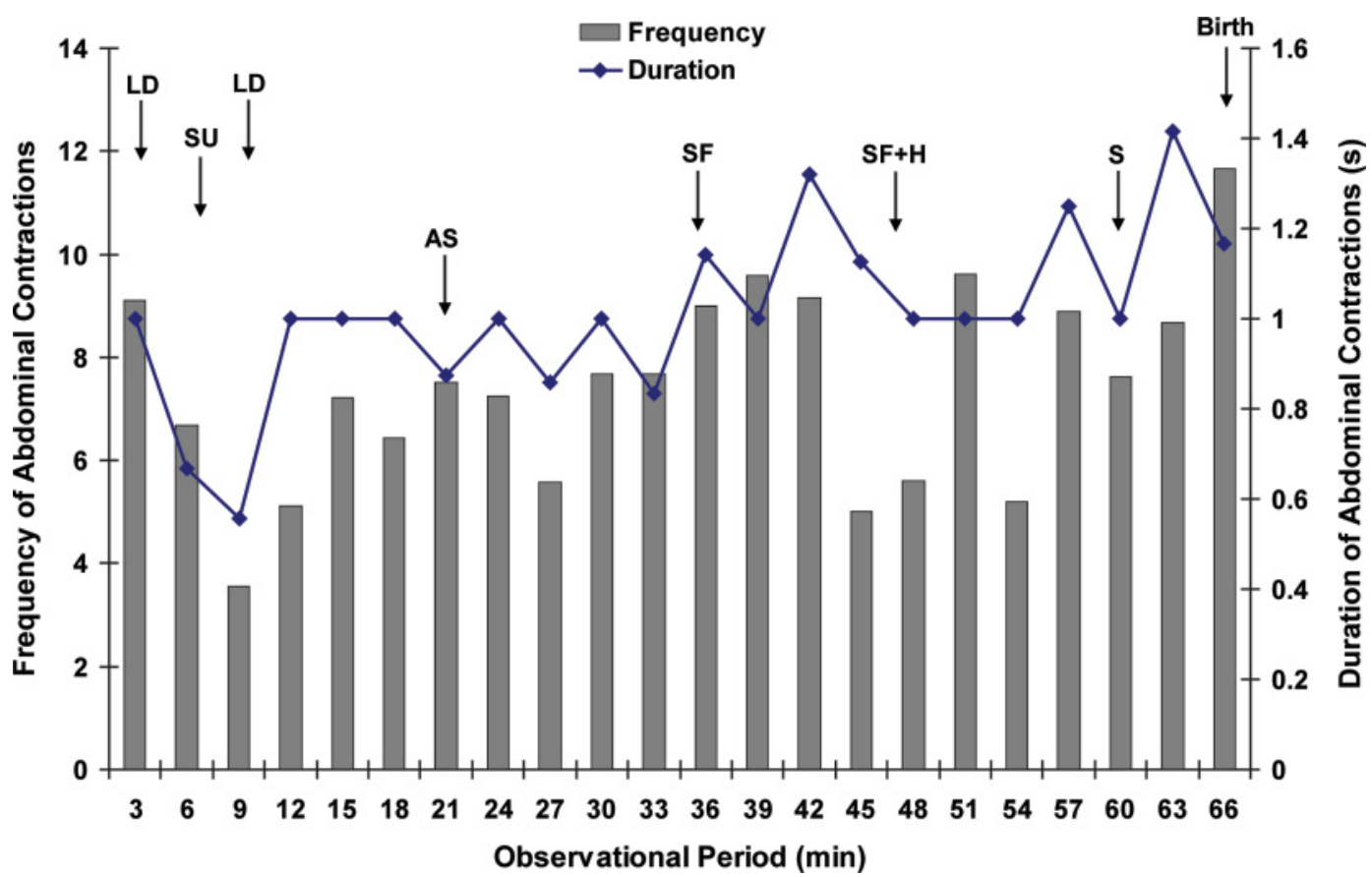

Figure 2. Mean frequency and duration (s) of abdominal contractions during the labor stage of unassisted births (eutocia) in 5 primiparous dairy cows. Periparturient primiparous cows $(\mathrm{n}=5)$ were placed in an individual maternity pen and constantly monitored until birth. Cow behavior (lying down or standing up), signs and progress of imminent birth (amniotic sac appearance, showing feet, head, shoulder, and birth), and the onset of frequency and duration of abdominal contractions were recorded during the labor stage of unassisted births (eutocia). The following calving signs over time (indication of birth progress) were recorded: $\mathrm{LD}=$ lying down; $\mathrm{SU}=$ standing up; AS = amniotic sac appearance; $\mathrm{SF}=$ showing feet; $\mathrm{SF}+\mathrm{H}=$ showing feet and head; $\mathrm{S}=$ shoulder; and birth. Color version available in the online PDF

dystocic births $(\mathrm{n}=5$; Figure 3$)$. The calving process was divided into 3 stages (Noakes et al., 2001; USDA, 2010), and under normal conditions (eutocia), it progresses gradually from one stage to the next. Enlargement of the udder, relaxation of the pelvic ligaments (i.e., swelling of the vulva), and discharge of vaginal fluids are common signs of imminent births in primiparous and multiparous cows. Dilation phase (stage I) is characterized by cervical dilation (i.e., ligaments and joint of the pelvic bone) and uterine contractions. Although variation in behavioral signs exist between cows and first-calving heifers, stage I is characterized by olfactory ground checks, nest-building-like behavior, licking their own bodies (e.g., hind back and limbs), vocalization, discharge of feces, restlessness (i.e., walking, standing up, and lying down), and tail raising (Wehrend et al., 2006; Miedema et al., 2011). Some of these behavioral signs such as tail raising, restlessness, and vocalization extend into stage II of labor. Stage I ends with a fully dilated cervix (Noakes et al., 2001; USDA, 2010). Expulsion phase (stage II) is characterized by the appearance of the AS outside the vulva, abdominal contractions are evident, and the calf (feet, nose, and head) progresses through the birth canal; stage II ends with the delivery of the calf (Noakes et al., 2001;
USDA, 2010). At the onset of stage II, cows usually lie down as the calf enters the birth canal. Expulsion of fetal membranes (stage III) is characterized by the passage of fetal membranes within the first $24 \mathrm{~h}$ after birth (Kelton et al., 1998; LeBlanc, 2008).

During the expulsion phase, MULT cows were characterized by lying down at the onset of the abdominal contractions and remaining recumbent until birth (Figure 1). The AS appeared about 10 min after the first set of abdominal contractions (Figure 1). About every 15 min, calving progress was characterized by the appearance of the calf feet, showing feet and head, showing shoulder outside the vulva, and birth (Figure 1). Once the head and shoulder of the calf was out of the vulva, a set of about 3 intense abdominal contractions completed the birth (Figure 1). However, PRIM cows showed restless behavior characterized by increased frequency of lying-standing positions at the beginning of labor stage (Figure 2). Thereafter, birth was characterized by recumbent position and abdominal contractions during the labor stage period comparable to MULT cows with clear calving progress every 15 min (Figure 2).

Dystocic births were characterized by abdominal contractions for about 95 min until intervention (Figure 3) during labor compared with eutocic births (Figures 


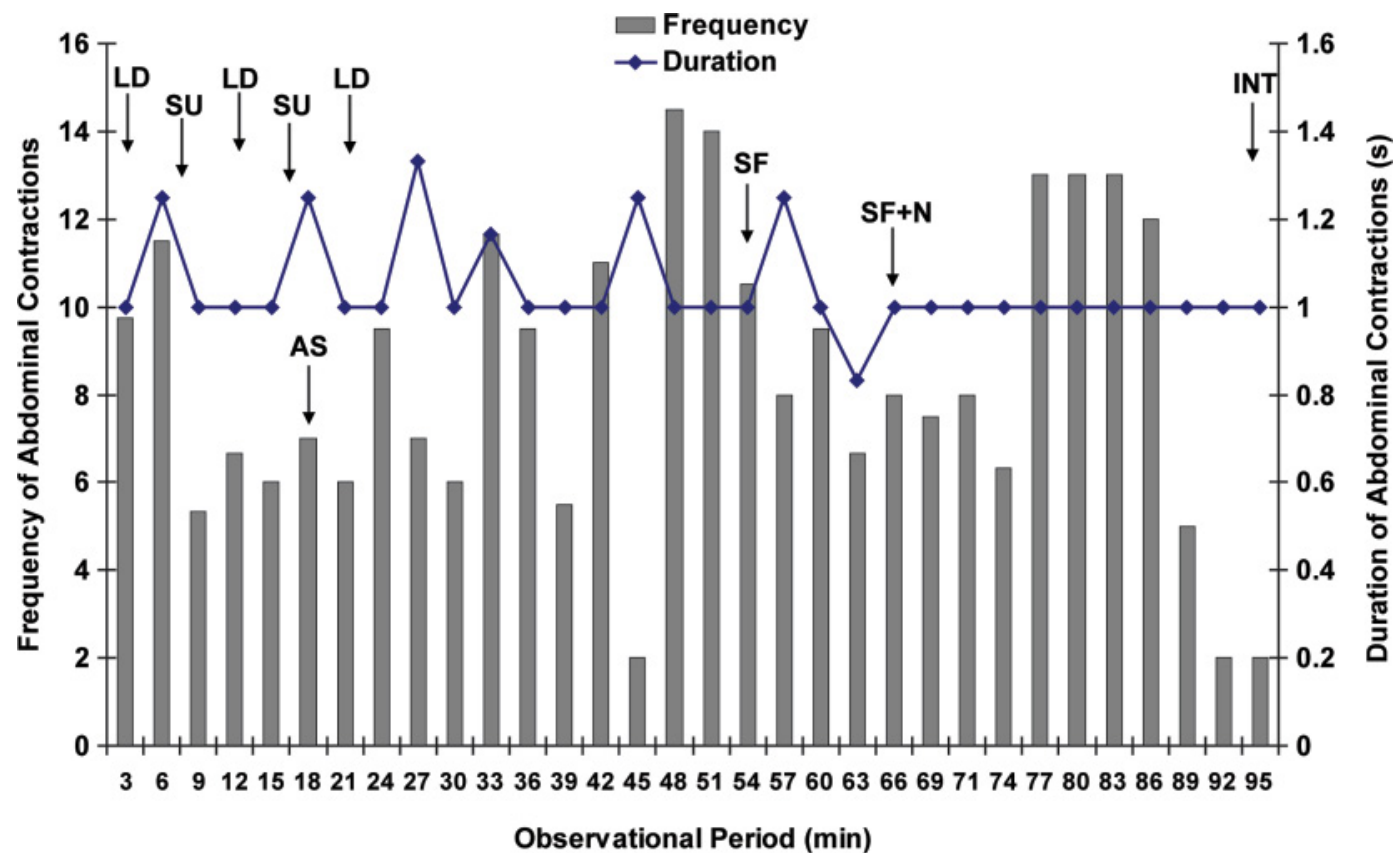

Figure 3. Mean frequency and duration (s) of abdominal contractions during the labor stage of assisted births (dystocia) in 5 primiparous dairy cows. Periparturient primiparous cows $(\mathrm{n}=5)$ were placed in an individual maternity pen and constantly monitored until birth. Cow behavior (lying down or standing up), signs and progress of imminent birth (amniotic sac appearance, showing feet, head, shoulder, and birth), and the onset of frequency and duration of abdominal contractions were recorded during the labor stage of assisted births (dystocia). The following calving signs over time (indication of birth progress) were recorded: LD = lying down; SU = standing up; AS = amniotic sac appearance; $\mathrm{SF}=$ showing feet; $\mathrm{SF}+\mathrm{N}=$ showing feet and nose; and INT = intervention required due to lack of birth progress. Color version available in the online PDF.

1 and 2). The AS appeared about 18 min after the initiation of abdominal contractions, and the feet and nose of the calf appeared about $36 \mathrm{~min}$ and $48 \mathrm{~min}$ after the AS appearance, respectively (Figure 3). Despite the increased frequency and duration of abdominal contractions over time, intervention was required about 80 min after AS appearance due to lack of birth progress (Figure 3). Based on our clinical observations, the number of abdominal contractions was reduced immediately before intervention in dystocic births (an evidence of cow fatigue; Figure 3). Therefore, it is important that calving personnel assess the "time" that a cow is in labor to determine whether intervention is required. In this study, assisted cows showed restless behavior (lying bouts; Figure 3) compared with eutocic births. The assessment of cow behavior (e.g., lying bouts, walking) by using data loggers (Proudfoot et al., 2009) before and during calving needs further investigation. A recent study showed that cows with dystocia were more restless $24 \mathrm{~h}$ before calving than cows with normal calving (Proudfoot et al., 2009). Identifying early signs of dystocia (e.g., lying bouts) before birth would help calving personnel identify those cows at risk (and plan a triage) rather than waiting for the signs of intervention as discussed above. This approach may have a positive management effect on overall calf-cow survival and welfare.

\section{Obstetric Intervention}

Of the 92 cows monitored in this observational study, 60 had unassisted (eutocia or normal) and 32 had assisted births (dystocia or abnormal; Table 1). The distribution of cows with respect to twins, parity (PRIM vs. MULT), BCS of cows immediately after birth, and calf sex are reported in Table 1. It is important to note that this study was conducted on one farm under the field conditions described previously. Although BCS was not different between PRIM and MULT cows in the present study (Table 1), it is generally accepted that overconditioning (Noakes et al., 2001) or BCS loss during the dry-off period (Gearhart et al., 1990) predisposes cows to dystocia. Further investigation is needed in herds with different characteristics such as BCS and breed to determine the effects on calving progress. Calf weight recorded immediately after birth $(P=0.03)$ and the proportion of stillbirths $(P<0.0001)$ were significantly associated with dystocia (Table 2). Factors such as calf size in relation to dam size, twins, uterine torsion, and malposition of the calf contribute to calv- 
ing difficulty (Mee, 2008; USDA, 2010). For instance, in PRIM cows, an important factor is the relationship between the calf size and the size of the birth canal (Mee, 2008). In MULT cows, dystocia is often related to twins or malposition of the calf (Mee, 2008; USDA, 2010). It was estimated that the dystocia rate increases by $13 \%$ per additional kilogram above a birth weight of $40.3 \mathrm{~kg}$ for Holstein cows (Johanson and Berger, 2003). For cows that need assistance at birth, timed intervention may reduce the negative effects of dystocia (e.g., due to increased calf birth weight or malpositions) on stillbirths, as observed in this study and elsewhere (Johanson and Berger, 2003). An intervention 60 min after the AS appearance outside the vulva reduced the proportion of stillbirths (by 9 percentage points; from 15.5 to $6.5 \%$ ), at least in part for those cows that needed light assistance at birth (Schuenemann et al., 2011). In this study, intervention was provided approximately 80 min after AS appearance.

For unassisted births, the time from AS appearance to birth was not different $(P=0.5)$ for PRIM $(45.8$ min; 95\% CI: 34.7-56.8) and MULT (44.3 min; 95\% CI: 30.7-58.7) cows. For cows that received assistance at birth, the time from AS appearance to birth was not different $(P=0.5)$ for PRIM $(89.9 \mathrm{~min}$; $95 \% \mathrm{CI}$ : 75.7-104.7) and MULT (79.7 min; 95\% CI: 58.7-100.7) cows. However, the overall time from AS or feet appearance outside the vulva to birth differed $(P<0.05)$ for unassisted cows compared with assisted cows (Table 2 ). The mean times (as LSM) from AS and feet appearance, respectively, to birth were 45.1 and $39.8 \mathrm{~min}$ for eutocic births (Table 2). The reference times for obstetric intervention during dystocia were estimated based on the mean +2 SD (Wenz et al., 2011) for unassisted births (Table 2). The estimated reference times from AS appearance to birth were 69.7 min (mean + $2 \mathrm{SD}$ ) and $54 \mathrm{~min}$ (upper limit of 95\% CI) for unassisted cows (Table 2). The reference times from feet appearance to birth were 64.6 min (mean $+2 \mathrm{SD}$ ) and 48 min (upper limit of 95\% CI) for unassisted cows (Table 2). At the time of difficult birth, determining the appropriate time for intervention is paramount for positive outcomes (for both calf and dam survival). According to the National Animal Health Monitoring System, $95 \%$ of dairy operators surveyed reported that they examine or assist PRIM and MULT cows within $3 \mathrm{~h}$ of the AS appearance at the vulva (USDA, 2010). Recognizing the signs of imminent birth and the timing for normal calving progress (from AS appearance to birth) are important to determine whether a cow needs assistance at calving. Regardless of parity, results from this observational study provided evidence that calving personnel should start assisting cows $70 \mathrm{~min}$ after AS appearance (or 65 min after feet appearance) outside the vulva (as described for eutocic births). It is important to note that earlier obstetric intervention is required when a malposition is evident (e.g., appearance of one leg outside the vulva) immediately after AS appearance. Noakes et al. (2001) provided a clinical estimation for normal bovine births between $30 \mathrm{~min}$ and $4 \mathrm{~h}$, with an average of $70 \mathrm{~min}$; however, the breed of cows was not provided. During training of calving

Table 1. Distribution of calving ease (unassisted or assisted births) with respect to parity (primiparous or multiparous), twins, mean BCS of dams immediately after birth, and calf sex in 92 Holstein cows ${ }^{1}$

\begin{tabular}{|c|c|c|c|}
\hline Variable & $\begin{array}{l}\text { Unassisted births } \\
\text { (eutocia; } \mathrm{n}=60 \text { ) }\end{array}$ & $\begin{array}{c}\text { Assisted births } \\
\text { (dystocia; } \mathrm{n}=32 \text { ) }\end{array}$ & $P$-value \\
\hline \multicolumn{4}{|l|}{ Assistance score at birth ${ }^{2}$ (no.) } \\
\hline $1=$ no assistance provided & 60 & & \\
\hline $2=$ light assistance & - & 21 & \\
\hline $3=$ mechanical extraction & - & 9 & \\
\hline $4=$ severe dystocia & - & 2 & \\
\hline Parity (no.) & & & 0.75 \\
\hline Primiparous & 36 & 22 & \\
\hline Multiparous & 24 & 10 & \\
\hline Twins (no.) & 1 & 1 & - \\
\hline Mean BCS of dams immediately after birth ${ }^{3}$ & $3.43 \pm 0.41$ & $3.37 \pm 0.34$ & 0.22 \\
\hline Calf sex $(\%)$ & & & 0.60 \\
\hline Male & 46.67 & 56.25 & \\
\hline Female & 53.33 & 43.75 & \\
\hline
\end{tabular}

${ }^{1}$ Periparturient dairy cows $(\mathrm{n}=92)$ were placed in an individual maternity pen and constantly monitored for signs of calving during unassisted (eutocia) and assisted births (dystocia).

${ }^{2}$ Acording to farm protocol, assistance was provided to cows without calving progress approximately $80 \mathrm{~min}$ after the amniotic sac appearance. The amount of assistance $(1=$ no assistance provided; $2=$ light assistance by one person without the use of mechanical traction; $3=$ mechanical extraction of the calf with an obstetric calf-puller; and $4=$ severe dystocia, surgery or fetotomy needed) was recorded at birth.

${ }^{3}$ Ditribution of BCS (mean $\pm 2 \mathrm{SD}$ ) for assisted and unassisted births. Mean BCS immediately after birth was not significantly different between primiparous and multiparous cows $(P=0.52)$. 
Table 2. Estimated calf BW at birth, stillbirths, and time from amniotic sac (AS) or from feet of the calf appearance to birth during the labor stage of Holstein cows with unassisted $(\mathrm{n}=60)$ or assisted births $(\mathrm{n}=32)$

\begin{tabular}{lccc}
\hline Variable & $\begin{array}{c}\text { Unassisted births } \\
(\text { eutocia; } \mathrm{n}=60)\end{array}$ & $\begin{array}{c}\text { Assisted births } \\
(\text { dystocia; } \mathrm{n}=32)\end{array}$ & $P$-value \\
\hline Calf BW at birth $^{1}(\mathrm{~kg})$ & $39.8 \pm 1.05^{\mathrm{b}}$ & $42.8 \pm 0.95^{\mathrm{a}}$ & 0.03 \\
Stillbirths $^{2}(\%)$ & $1.5 \pm 3.4^{\mathrm{b}}$ & $22.1 \pm 3.5^{\mathrm{a}}$ & $<0.0001$ \\
Time from AS appearance to birth & & \\
LSM \pm SEM & & & \\
Mean \pm 2SD & $45.1 \pm 4.4^{\mathrm{b}}$ & $84.8 \pm 6.3^{\mathrm{a}}$ & $<0.0001$ \\
$95 \%$ CI & $45.2 \pm 24.5$ & $86.7 \pm 45.1$ & \\
Time from feet appearance to birth $^{3}(\mathrm{~min})$ & $36.3-53.8$ & $72.1-97.5$ & \\
LSM \pm SEM & $39.8 \pm 4.4^{\mathrm{b}}$ & $61.3 \pm 7.4^{\mathrm{a}}$ & 0.01 \\
Mean \pm 2SD & $38.9 \pm 25.7$ & $62.8 \pm 34.3$ & \\
$95 \%$ CI & $30.9-48.6$ & $45.7-73.6$ & \\
\hline
\end{tabular}

${ }^{\mathrm{a}, \mathrm{b}}$ Values with different superscript letters within a row differ significantly at $P<0.05$.

${ }^{1}$ Calf BW was recorded immediately after birth. Least squares means $( \pm \mathrm{SEM})$ were estimated for unassisted and assisted births.

${ }^{2}$ The proportion of stillborn calves was recorded for unassisted and assisted births. Stillbirth was defined as a calf born dead or that died within $24 \mathrm{~h}$ after birth.

${ }^{3}$ Periparturient dairy cows were placed in an individual maternity pen and the time (min) from the AS appearance to birth as well as from the feet of the calf appearance outside the vulva to birth were recorded. Least squares means $( \pm \mathrm{SEM})$, mean $( \pm 2 \mathrm{SD})$, and $95 \%$ CI were estimated for unassisted and assisted births.

personnel, instructors must provide clear guidelines on the signs of imminent birth, obstetric strategies (e.g., how to correct malpositions or presentations), hygiene practices, frequency of observations, record keeping, and the appropriate time for intervention. Hands-on demonstrations should always be available immediately after instruction not only to highlight key learning objectives, but also to provide critical feedback to participants and to make any necessary clarification. Dairy personnel have expressed strong support for these learning methodologies (Schuenemann et al., 2011).

\section{CONCLUSIONS}

These findings have important implications for dairy personnel executing calving tasks. Cows with assisted births (dystocia) had a longer period from the AS or feet appearance to birth and increased incidence of stillbirths compared with cows with unassisted calving. Although not significant, it is important to note that the time spent in labor varied for PRIM and MULT cows. This study suggested that calving personnel should start assisting cows 70 min after AS appearance (or 65 min after feet appearance) outside the vulva (based on eutocic births). Under field conditions, the observation of AS or feet appearance outside the vulva as well as calving progress are clear and concrete landmarks that calving personnel can easily identify. Early intervention has the potential to prevent stillbirths, but also has the potential for dam injury due to lack of proper dilation of soft tissues. When a malposition is evident (e.g., appearance of one foot outside the vulva) immediately after AS appearance, or for uterine torsions (where the AS or feet do not appear outside the vulva), obstetric intervention is rendered. The time spent in labor (straining) combined with the time from the AS or feet appearance to birth and the assessment of calving progress (as described for eutocic births) should be used as guidelines to determine the appropriate time for intervention during difficult births under field conditions. These reference times should be interpreted in combination with adequate obstetrical knowledge and examination.

\section{ACKNOWLEDGMENTS}

The authors thank the collaborating dairy farm and the staff for providing the animals used in this study. The comments and suggestions of the anonymous reviewers are greatly appreciated.

\section{REFERENCES}

Berger, P. J., A. C. Cubas, K. J. Koehler, and M. H. Healey. 1992. Factors affecting dystocia and early calf mortality in Angus cows and heifers. J. Anim. Sci. 70:1775-1786.

Curtis, C. R., H. N. Erb, C. J. Sniffen, R. D. Smith, P. A. Powers, M. C. Smith, M. E. White, R. B. Hilman, and E. J. Pearson. 1983 Association of parturient hypocalcaemia with eight periparturient disorders in Holstein cows. J. Am. Vet. Med. Assoc. 183:559-561.

Dematawewa, C. B. M., and P. J. Berger. 1997. Effect of dystocia on yield, fertility, and cow losses and an economic evaluation of dystocia scores for Holsteins. J. Dairy Sci. 80:754-761.

Ferguson, J. D., D. T. Galligan, and N. Thomsen. 1994. Principal descriptors of body condition in Holstein dairy cattle. J. Dairy Sci. 77:2695-2703.

Frazer, G. S., M. Perkins, and P. Constable. 1996. Bovine uterine torsion: 164 hospital referral cases. Theriogenology 46:739-758.

Gearhart, M. A., C. R. Curtis, H. N. Erb, R. D. Smith, C. J. Sniffen, L. E. Chase, and M. D. Cooper. 1990. Relationship of changes in 
condition score to cow health in Holsteins. J. Dairy Sci. 73:31323140 .

Johanson, J. M., and P. J. Berger. 2003. Birthweight as a predictor of calving ease and perinatal mortality in Holstein cattle. J. Dairy Sci. 86:3745-3755.

Kelton, D. F., K. D. Lissemore, and R. E. Martin. 1998. Recommendations for recording and calculating the incidence of selected clinical diseases of dairy cattle. J. Dairy Sci. 81:2502-2509.

LeBlanc, S. J. 2008. Postpartum uterine disease and dairy herd reproductive performance: A review. Vet. J. 176:102-114.

Lombard, J. E., F. B. Garry, S. M. Tomlinson, and L. P. Garber. 2007. Impacts of dystocia on health and survival of dairy calves. J. Dairy Sci. 90:1751-1760.

Mee, J. F. 2004. Managing the dairy cow at calving time. Vet. Clin. North Am. Food Anim. Pract. 20:521-546.

Mee, J. F. 2008. Prevalence and risk factors for dystocia in dairy cattle: A review. Vet. J. 176:93-101.

Meijering, A. 1984. Dystocia and stillbirths in cattle - A review of causes, relations and implications. Livest. Prod. Sci. 11:143-177.

Meyer, C. L., P. J. Berger, K. J. Koehler, J. R. Thompson, and C. G. Sattler. 2001. Phenotypic trends in incidence of stillbirth for Holsteins in the United States. J. Dairy Sci. 84:515-523.

Miedema, H. M., M. S. Cockram, C. M. Dwyer, and A. I. Macrae. 2011. Behavioural predictors of the start of normal and dystocic calving in dairy cows and heifers. Appl. Anim. Behav. Sci. 131:14-19.

Noakes, D. E., T. J. Parkinson, and G. C. W. England. 2001. Dystocia and other disorders associated with parturition. Arthur's Veterinary Reproduction and Obstetrics. 8th ed. Saunders, Philadelphia, PA.
NRC. 2001, Nutrient Requirements of Dairy Cattle. 7th rev. ed. National Academy Press, Washington, DC

Proudfoot, K. L., J. M. Huzzey, and M. A. von Keyserlingk. 2009. The effect of dystocia on the dry matter intake and behavior of Holstein cows. J. Dairy Sci. 92:4937-4944.

SAS Institute. 2009. SAS/STAT 9.2 User's Guide. 2nd ed. SAS Institute Inc., Cary, NC.

Schuenemann, G.M., S. Bas, E. Gordon, and J. Workman. 2011. Dairy calving management: Assessment of a comprehensive program for dairy personnel. J. Dairy Sci. 94(E-Suppl. 1):483. (Abstr.)

Sheldon, I. M., J. Cronin, L. Goetze, G. Donofrio, and H.-J. Schuberth. 2009. Defining postpartum uterine disease and the mechanisms of infection and immunity in the female reproductive tract in cattle. Biol. Reprod. 81:1025-1032.

Smit, W., P. van Dijk, M. J. Langedijk, N. Schouten, N. van den Berg, D. G. Struijk, and R. T. Krediet. 2003. Peritoneal function and assessment of reference values using a $3.86 \%$ glucose solution. Perit. Dial. Int. 23:440-449.

USDA. 2010. Dairy 2007, Heifer Calf Health and Management Practices on U.S. Dairy Operations, 2007. USDA:APHIS:VS, CEAH, Fort Collins, CO.

Wehrend, A., E. Hofmann, K. Failing, and H. Bostedt. 2006. Behaviour during the first stage of labour in cattle: Influence of parity and dystocia. Appl. Anim. Behav. Sci. 100:164-170.

Wenz, J. R., D. A. Moore, and R. Kasimanickam. 2011. Factors associated with the rectal temperature of Holstein dairy cows during the first 10 days in milk. J. Dairy Sci. 94:1864-1872. 